\title{
Chronic Carrageenan Toxicity and the Possible Ameliorative Role of Diacerein in Experimental Animals
}

\author{
Shereen Abdelhakim Abdelaleem, Eman Ismail Hasan', Nashwa Fathy El-Tahawy', and Doaa Mohamed Elroby Ali ${ }^{3}$
}

${ }^{1}$ Department of Forensic medicine and Toxicology.

${ }^{2}$ Department of Histology.

${ }^{3}$ Department of Biochemistry.

Faculty of Medicine- Minia University- Faculty of Pharmacy-DerayaUniversity.

\begin{abstract}
Carrageenan, is one of the food additives and is used as a firming agent in healthcare products like toothpaste. The aim of this study was to analyze the chronic toxic effects of kappa carregeenan (k- CGN) on the thyroid gland and pancreas in experimental rats and to evaluate the possible ameliorative effect of Diacerein. This study was done on fifty adult male albino rats. The rats were divided into 5 groups (10 rats in each group) in the form of; control group, Carboxymethylcellulose group $(1.2 \mathrm{ml} / \mathrm{Kg})$, Diacerein group $(30 \mathrm{mg} / \mathrm{Kg})$, Carrageenan group $(50 \mathrm{mg} / \mathrm{Kg})$, and Diacerein( $30 \mathrm{mg} / \mathrm{kg})+$ Carrageenan $(50 \mathrm{mg} / \mathrm{kg})$ combination group All drugs were given orally for 3 months. By the end of the $3^{\text {rd }}$ month, thyroid and pancreatic functions were assessed by biochemical, histological, and immunohistochemical investigations. Rats group that were given Carrageenan alone had significantly higher thyroid MDA (malondialdehyde), lower thyroid GSH (reduced glutathione) and serum T4 levels than the untreated control rats group, but co- treatment of Carrageenan- exposed rats with diacerein had an ameliorative effect on the previous results. Light microscopic examinations of thyroid gland sections revealed that Carrageenan caused significant marked hypothyroid changes, and significant mild hypothyroid changes were observed in the rats which received Carrageenan + diacerein combination. Immunohistochemical studies of thyroid gland showed that carrageenan caused significant marked expression of PCNA and significant mild expression was observed in rats received combination of diacerein + carrageenan. Regarding pancreas, this study revealed no significant statistical changes in serum amylase level, MDA and GSH levels. Also, there were not any significant pathological changes of pancreatic tissues of carrageenan group. Thus, it appears that carrageenan can induce oxidative damage in the thyroid gland of rats and diacerein has an ameliorative effect against this damage.
\end{abstract}

\begin{tabular}{l|l} 
Keywords & Carrageenan, thyroid, pancreas, PCNA, diacerein.
\end{tabular}

\section{Introduction}

C arrageenan (CGN) is a high molecular weight sulfated polygalactan derived from a number of species of red seaweeds of the class Rhodophyceae. It is a polymer of the sugar, galactose, composed of repeating galactose units that may have sulfate groups attached. The prevalent copolymers in CGN are designated as kappa- (k), iota- ( $(\mathrm{i})$, and lambda ( $\lambda$ ) (Blakemore \& Harpell, 2010).

Carrageenans are used in a variety of commercial applications as gelling, thickening, and stabilising agents, especially in food products and sauces. Aside from these functions, carrageenans are used in experimental medicine, pharmaceutical formulations, cosmetics, and industrial applications (Necas \& Bartosikova, 2013). Its use increased markedly during the last half century, although carrageenan is known to induce inflammation in rheumatological models and in intestinal models of colitis (Borthakur et al., 2007).

Kappa carrageenan derived from a species of seaweed called Kappaphycus alvarezii, hence its name "kappa carrageenan". "k- CGN" is used as a firming agent to provide textures ranging from soft to very firm. It is essential for producing the finest non-dairy cheeses that mimic dairy cheeses in texture and melt-ability (Yuan et al., 2006). K-CGN is mostly the alternating 
polymer of D-galactose-4-sulfate and 3, 6-anhydro-Dgalactose. The anionic ester sulfate groups on CGN bind to positively charged groups on food proteins, imparting functionality as a thickener and stabilizer in foods (Blakemore \& Harpell, 2010).

Diacerein is a compound with anti-inflammatory properties that inhibits the synthesis and activity of proinflammatory cytokines, such as TNF- $\alpha$ and interleukin 1. The active metabolite for diacerein is rhein $(1,8-$ dihydroxy-3-carboxyanthraquinone), which is found in plants of the genus Cassia and has exhibited antiinflammatory effects by inhibiting cytokine synthesis (Torina et al., 2015). Since it does not inhibit prostaglandins, diacerein does not have a deleterious effect on the upper gastrointestinal mucosa (Pavelka et al., 2007).

Proliferating cell nuclear antigen (PCNA) is a protein found in all eukaryotic species as well as in Archaea. PCNA was first shown to act as a processivity factor of DNA polymerase $\delta$, which is required for DNA synthesis during replication. However, besides DNA replication, PCNA functions are associated with other vital cellular processes such as chromatin remodelling, DNA repair, sister-chromatid cohesion and cell cycle control. This protein was identified over 30 years ago as an antigen for an autoimmune disease in the serum of patients with systemic lupus erythematosus. It was shown that expression levels of PCNA are associated with proliferation or neoplastic transformation (Strzalka \& Ziemienowicz, 2011)

Owed to the few number of researches evaluating the chronic toxic effects of Carragenan and the possible protective effects of Diacerein, the objective of this study was to assess the effects of chronic carrageenan exposure on thyroid gland and pancreas, and evaluate the influence of diacerein administration on these effects.

\section{Materials \& Methods}

\section{Animals}

This work was carried out on 50 adult Wistar male albino rats (weighing approximately 200- $250 \mathrm{gm}$ ) of twelve weeks of age. The animals were obtained from Minia University Laboratory Animals Growing Center. The rats were housed in plastic cages, fed a standard laboratory diet and water and maintained at a laboratory temperature of $22 \pm 3^{\circ} \mathrm{C}$ and exposed to a 12 light, dark cycle. All aspects of animal care and treatment were carried out according to the local guide lines of the Ethical Committee of Faculty of Medicine- Minia University.

\section{Drugs \& Kits}

Diacerein (capsules) 50mg was obtained from Evapharm Company (Cairo-Egypt). Kappa-Carrageenan (Powder) 25gm and carboxymethylcellulose $5 \%$ solution which is acting as a solvent for Diacerein were obtained from Sigma-Aldrich Company (Cairo- Egypt). Kits for T3 , T4 hormones, amylase enzyme, malondialdehyde (MDA) and reduced glutathione (GSH) were obtained from Bio-diagnostic Company, Egypt. Epitope specific antibody to PCNA was purchased from Thermo Fisher Scientific Anatomical Pathology (CA, USA).

\section{Calculation of the ingested dose:}

1 - Diacererin: 100mg dissolved in $4 \mathrm{ml}$ carboxymethylcellulose $5 \%$ solution. A dose of 30 $\mathrm{mg} / \mathrm{kg} /$ day was given orally $30 \mathrm{~min}$ before carrageenan by a gavage for 3 months. This anti-inflammatory and antioxidant dose was chosen according to (Jatwa \& Kar, 2009 and Marwa et al., 2016).

2- Kappa-carrageenan: 100mg dissolved in 10 $\mathrm{ml}$ distilled water. A dose of $50 \mathrm{mg} / \mathrm{kg} /$ day $(1.08 \%$ of oral $\mathrm{LD}_{50}$ ) was given orally by a gavage for 3 months (Tobacman, 2001). The oral $\mathrm{LD}_{50}$ of Carrageenan in rats is $5400 \mathrm{mg} / \mathrm{Kg}$ (Lai et al., 2000).

\section{Experimental protocol}

The animals were divided into 5 groups each composed of 10 rats as follow:

Group 1 ( -ve control group): fed a standard laboratory diet and water to show the normal parameters.

Group II (+ve control group) (10 rats): each rat was given carboxymethylcellulose $5 \%$ solution by gavages in a dose of $1.2 \mathrm{ml} / \mathrm{kg} /$ day.

Group III (10 rats): each rat was given diacerein by gavages in a dose of $30 \mathrm{mg} / \mathrm{kg} /$ day.

Group IV (10 rats): each rat was given carragenan by gavages in a dose of $50 \mathrm{mg} / \mathrm{kg} /$ day.

Group V (10 rats): each rat was given diacerein then carragenan (after $30 \mathrm{~min}$ ) in same previous doses.

The animals were acclimatized prior to starting dosing for a period of one week. All approved conditions used for animal housing and handling were considered. The experimental protocol used followed the regulations for administration and painless sacrifice of the experimental animals. Rats were sacrificed by decapitation after light ether anesthesia and dissected at the end of the experiment. The thyroid gland and pancreas were dissected and subjected to light and immunohistochemical investigation. The remaining thyroid gland and pancreatic tissues were subjected to biochemical studies (malondialdehyde (MDA), reduced glutathione (GSH) levels). Blood samples were collected for assaying the level of T3, T4 hormones and amylase enzyme levels.

\section{Biochemical studies}

At the end of $3^{\text {rd }}$ month , blood samples were withdrawn from the retro-orbital plexus of veins using a capillary pipette and collected in heparinised tubes and centrifuged at $3000 \mathrm{rPm}$ for $15 \mathrm{~min}$. and stored at $-20^{\circ} \mathrm{C}$ until required. The samples were subjected for the estimation of:

1-T3 and T4 hormones: They were measured by ELISA kits at absorbance wave length $45 \mathrm{~nm}$ by ELISA reader (Stat Fax-2100 microplate reader, Awareness Technology inc., Palm city) (Chen et al., 2017)

2-Amylase enzyme level: It was measured by ELISA kits (Biely et al., 1988). 
Malondialdehyde(MDA) and reduced glutathione (GSH) assays: Parts of thyroid gland and pancreas were separated and homogenized in 1:10 (wt: vol) $0.1 \mathrm{M}$ phosphate buffer $(\mathrm{pH} 7.4)$ by the use of a Teflon headed homogenizer. Triton x100 and protease inhibitor cocktail were added. The homogenates were centrifuged at $6.000 \mathrm{~g}$ for $10 \mathrm{~min}$ at $4^{\circ} \mathrm{C}$ and the supernatant was used to measure MDA and GSH. MDA was measured as described by Ohkawa et al. (1979). While GSH was measured according to Beutler et al. (1963).

\section{Histopathological study}

Thyroid and pancreatic specimens were fixed in $10 \%$ buffered formalin for 24 hours, dehydrated in a graded alcohol series, cleared in xylene, and embedded in paraffin. put in $10 \%$ formalin and embedded in paraffin for histopathological examination and immunohistochemical assay of PCNA. Serial sections from the paraffin-embedded tissues were cut at $5 \mu \mathrm{m}$ thick, where one section was stained with haematoxylin \& eosin (H\&E) for routine histopathological examination (Bancroft et al., 2002) and the rest of sections were used for immunohistochemical staining to be viewed by Olympus light microscope (Olympus BX51, Tokyo, Japan) with an attached camera (Cannon 620). Brightness, contrast were adjusted using Adobe Photoshop software.

\section{Assessment of Immunohistochemical study( immuno-expression of PCNA):}

$5 \mu$-thichness paraffin sections were used for immunostaining for anti-PCNA antibody (ready to use) according to the manufacture's guidelines. Sections were deparaffinized, rehydrated, immersed in $0.1 \%$ hydrogen peroxide (for 15 minutes), and washed by phosphate buffer. Then incubated in the ultravision block for 5 minutes at room temperature. Sections were incubated with anti-PCNA antibody for 60 minutes at room temperature. Its reaction was visualized by using: Ultravision one detection System, HRP Polymer \& diaminiobenzide (DAB) Plus Chromogen. Sections were dehydrated, cleared, and mounted on glass slides for further staining with haematoxylin \& eosin (H \&E) (ElTahawy et al., 2017).

Morphometric study for the assessment of immuno-expression of PCNA:

The immunolabeled cells were counted. In each animal, 3 sections were examined, and cells were counted in 3 adjacent non overlapping fields. In each section, three high-power fields $(\times 400)$ were selected for assessment of immunoreactivity score (IRS). IRS was defined as the product of staining intensity (SI) and the percentage of positive cells (PP). Staining intensity was graded as 0 (negative), 1 (weak), 2 (modarate), and 3 (strong); percentage of positive cells examined was scored as 0 (negative), 1 (< 10\%), 2 (11-50\%), 3 (51$80 \%)$, and 4 (> $80 \%)$. IRS values was from $0-12$ as follow: 0 as negative, $1-3$ as weak, values 4,6 as moderate positive, and multiplication values $8,9,12$ as strongly positive (Metindir et al., 2008).

\section{Statistical analysis}

Analysis of results was carried out using SPSS version 20. The following statistical tests were used: (1) Mean and standard deviation $(\mathrm{M} \pm \mathrm{SD})$ to describe quantitative data. (2) Analysis of results of parametric quantitative data and the significance of differences was calculated by using ANOVA test with Post Hoc LSD analysis for comparison between groups. (3) Chi-square test was done to calculate the significance for non-parametric data. $\mathbf{P} \leq 0.05$ was considered significant.

\section{Results}

\section{I- Results of biochemical studies}

There was insignificant decrease in T3 level in all groups compared to control group. Treatment of diacerein before carrageenan induced insignificant decrease compared to carrageenan treated group (table 1). Regarding T4 level, There was insignificant decrease in T4 level in Group II \& III when compared to control group. Carraganeen-treated rats had significant decrease in T4 level compared to all other groups. Administration of Diacerein with Carrageenan resulted in significant increase in T4 level (table 2). Table (3) showed insignificant decrease in serum amylase level in groups II, III, IV and V compared to control group. The decrease in Serum amylase level did not change by administration of diacerein perior to caraganeen .

There was significant increase in MDA level in thyroid gland in groups IV and V compared to groups I, II and III. MDA level was significantly decreased by administration of diacerein before carageenan in group $\mathrm{V}$ compared to diacerein treated group but still not reached to control level (table 4). Table (5) revealed that there was insignificant increase in MDA level in pancreas in all groups compared to control group and this insignificant increase not changed by administration of diacerein.

Table (6) showed that GSH level in thyroid gland was significantly decreased in carageenan treated group compared to control group. Diacerein + carageenan treated group (IV) caused significant increase in GSH level compared to carageenan treated group (V) but not reached to control level. There was insignificant decrease in GSH level in pancreas in groups IV and V compared to group I and this insignificant decrease not changed by administration of diacerein (table 7).

\section{II- Histopathological results:}

A- Light microscopic examinations of thyroid gland:

Light microscopic examinations of thyroid glands revealed that sections from control, carboxymethylcellulose, and diacerein groups showed normal architecture. The gland was formed of variable sized follicles arranged in lobules with the large follicles at the periphery. Lumina were filled with colloid and surrounded by a single layer of flattened to cubical cells. 
The interfollicular cells were noticed in groups between follicles. (Fig.1, table 8).

Carrageenan group had variable and patchy morphological changes; loss of lobular architecture, numerous small-sized follicles with reduction of colloid or completely empty Lumina. Most of epithelial lining of follicles were flattened. Some cells were exfoliated in the lumen. Some follicles showed follicular membrane disruption and vascular congestion (Fig.2, table 8). In the Diacerein+ Carrageenan - treated group, the changes were milder than that of the previous group. Few smallsized follicles were shown with reduction of colloid, and the inter-follicular area was more wide than normal (Fig.3, table 8).

\section{B-Light microscopic examinations of pancreas :}

Light microscopic sections of pancreas from the control, carboxymethylcellulose, and diacerein groups showed showed normal lobular structure with delicate interlobular connective tissue. Numerous islets of Langerhans scattered between the pancreatic acini. The islet appeared lightly stained and consisted of cords of polygonal cells separated by blood capillaries. The acinar cells were characterized by its basal basophilia and apical acidophilia (Fig.4, table 9).

Most of the pancreatic sections of the carrageenan group appeared normal except sections from few rats that showed variable morphological changes of acute pancreatitis. Histological signs of acute pancreatitis included widening of the inter-lobular spaces (edema), and vacuolar degeneration of the pancreatic lobules. Blood vessels in the interstitium were markedly congested inflammatory cells infiltration. Some islets showed degenerations as some cells appeared with nuclear pyknosis and dense acidophilic cytoplasm while other cells showed vaculated cytoplasm and ghosts of nuclei (Fig.5, table 9). Treatment with Diacerein before Carrageenan kept the normal histological architecture of the pancreas. There was some widening of the interlobular spaces (Fig.6, table 9).

III-Immunohistochemical analysis of sections immunostained with PCNA:

Immunohistochemical analysis of thyroid gland showed that control, carboxymethylcellulose, and diacerein groups showed few positive nuclear expressions for PCNA (fig.7). Carrageenan group showed no immunopositive cells, flattening of most cells, and disruption of epithelial lining (fig.8). Diacerein+ Carrageenan had obvious increase of the immunolabeled cells (Fig.9).Carraganeen (group IV) had significantly lower IRS than other groups, while IRS showed significant increase when comparing group $\mathrm{V}$ with other groups (table 10). While, in pancreatic tissues, the first 3 groups showed few immunolabelled cells (fig. 10). Carageenan group showed no immunolabeled cells (fig.11). Diacerein + Carrageenan group showed some immunolabeled cells in the acini (A) and duct (D) (fig.12). IRS showed insignificant change when comparing any group with the other groups (table 11).

Table (1): One way ANOVA statistical analysis of serum T3 level in different experimental groups

\begin{tabular}{|c|c|c|c|c|c|}
\hline & \multirow{2}{*}{ Mean \pm SD } & \multicolumn{4}{|c|}{$P=0.74$} \\
\hline & & vs II & vs III & vs IV & vs V \\
\hline Group I & $2.28 \pm 0.18$ & 0.722 & 0.88 & 0.93 & 0.76 \\
\hline Group II & $1.96 \pm 0.48$ & & 0.99 & 0.97 & 0.98 \\
\hline Group III & $2.04 \pm 0.54$ & & & 0.99 & 0.9 \\
\hline Group IV & $2.0 \pm 0.39$ & & & & 0.89 \\
\hline Group V & $2.01 \pm 0.38$ & & & & \\
\hline
\end{tabular}

Table (2): One way ANOVA statistical analysis of serum T4 level in different experimental groups

\begin{tabular}{|l|l|l|l|l|l|}
\hline \multicolumn{2}{|c|}{ Mean \pm SD } & \multicolumn{4}{|c|}{ P value } \\
\cline { 3 - 6 } & & vs II & vs III & vs IV & vs V \\
\hline Group I & $17.22 \pm 0.48$ & 0.55 & 0.49 & $0.001^{*}$ & $0.002^{*}$ \\
\hline Group II & $16.54 \pm 0.73$ & & 0.9 & $0.001^{*}$ & $0.04^{*}$ \\
\hline Group III & $16.38 \pm 0.53$ & & & $0.001^{*}$ & 0.17 \\
\hline Group IV & $11.46 \pm 1.15$ & & & & $0.001^{*}$ \\
\hline Group V & $15.33 \pm 0.68$ & & & & \\
\hline
\end{tabular}

${ }^{*} p<0.05$ is significant $\quad$ SD: standerded deviation the measurement unit is $\mu \mathrm{g} / \mathrm{dl}$ 
Table (3): One way ANOVA statistical analysis of serum amylase level in different experimental groups

\begin{tabular}{|l|c|l|l|l|l|}
\hline \multirow{2}{*}{ Mean \pm SD } & \multicolumn{5}{c|}{ P value } \\
\cline { 3 - 6 } & & vs II & vs III & vs IV & vs V \\
\hline Group I & $925.2 \pm 48.58$ & 0.89 & 0.9 & 0.52 & 0.71 \\
\hline Group II & $924.4 \pm 46.07$ & & 0.88 & 0.57 & 0.76 \\
\hline Group III & $924 \pm 44.69$ & & & 0.42 & 0.62 \\
\hline Group IV & $921.5 \pm 169.19$ & & & & 0.89 \\
\hline Group V & $918.56 \pm 103.45$ & & & & \\
\hline
\end{tabular}

${ }^{*} p<0.05$ is significant $\quad S D$ : standerded deviation $\quad$ the measurement unit is $I U / L$

Table (4): One way ANOVA statistical analysis of MDA level in thyroid gland in different experimental groups

\begin{tabular}{|c|c|c|c|c|c|}
\hline \multirow{2}{*}{ Mean \pm SD } & \multicolumn{4}{|c|}{ P value } & vs V \\
\cline { 3 - 6 } & & vs II & vs III & vs IV & v V \\
\hline Group I & $30.62 \pm 1.8$ & 0.55 & 0.49 & $0.001^{*}$ & $0.002^{*}$ \\
\hline Group II & $30.31 \pm 1.5$ & & 0.9 & $0.001^{*}$ & $0.09^{*}$ \\
\hline Group III & $31.22 \pm 2.1$ & & & $0.001^{*}$ & $0.017^{*}$ \\
\hline Group IV & $48.22 \pm 3.1$ & & & & $0.001^{*}$ \\
\hline Group V & $35.38 \pm 0.57$ & & & & \\
\hline
\end{tabular}

${ }^{*} p<0.05$ is significant $\quad$ SD: standerded deviation the measurement unit is nmol/gm tissue

Table (5): One way ANOVA statistical analysis of MDA level in pancreas in different experimental groups

\begin{tabular}{|c|c|c|c|c|c|}
\hline \multirow{2}{*}{ Mean \pm SD } & \multicolumn{4}{|c|}{ P value } \\
\cline { 3 - 6 } & & vs II & vs III & vs IV & vs V \\
\hline Group I & $28.64 \pm 1.2$ & 0.77 & 0.9 & 0.52 & 0.81 \\
\hline Group II & $29.2 \pm 1.5$ & & 0.62 & 0.73 & 0.62 \\
\hline Group III & $29.8 \pm 0.98$ & & & 0.46 & 0.72 \\
\hline Group IV & $30.08 \pm 3.1$ & & & & 0.89 \\
\hline Group V & $29.39 \pm 2.2$ & & & & \\
\hline
\end{tabular}

${ }^{*} p<0.05$ is significant $\quad$ SD: standerded deviation the measurement unit is $\mathrm{nmol} / \mathrm{gm}$ tissue

Table (6): One way ANOVA statistical analysis of GSH level in thyroid gland in different experimental groups

\begin{tabular}{|c|c|c|c|c|c|}
\hline \multirow{2}{*}{ Mean \pm SD } & \multicolumn{4}{|c|}{ P value } \\
\cline { 3 - 6 } & & vs II & vs III & vs IV & vs V \\
\hline Group I & $318.02 \pm 12.2$ & 0.35 & 0.49 & $0.001^{*}$ & $0.002^{*}$ \\
\hline Group II & $320.31 \pm 9.22$ & & 0.7 & $0.001^{*}$ & $0.002^{*}$ \\
\hline Group III & $318.22 \pm 11.08$ & & & $0.001^{*}$ & $0.007^{*}$ \\
\hline Group IV & $212.02 \pm 19.22$ & & & & $0.001^{*}$ \\
\hline Group V & $280.67 \pm 12.11$ & & & & \\
\hline
\end{tabular}

${ }^{*} p<0.05$ is significant $\quad S D$ : standerded deviation the measurement unit is $\mathrm{mg} / \mathrm{gm}$ tissue

Table (7): One way ANOVA statistical analysis of GSH level in pancreas in different experimental groups

\begin{tabular}{|c|c|c|c|c|c|}
\hline \multirow{2}{*}{ Mean \pm SD } & \multicolumn{4}{|c|}{ P value } \\
\cline { 3 - 5 } & & vs II & vs III & vs IV & vs V \\
\hline Group I & $150.2 \pm 3.4$ & 0.56 & 0.94 & 0.72 & 0.85 \\
\hline Group II & $151.02 \pm 4.2$ & & 0.42 & 0.53 & 0.62 \\
\hline Group III & $150.82 \pm 5.6$ & & & 0.56 & 0.52 \\
\hline Group IV & $148.88 \pm 5.2$ & & & & 0.83 \\
\hline Group V & $149.01 \pm 8.1$ & & & & \\
\hline
\end{tabular}

${ }^{*} p<0.05$ is significant $\quad$ SD: standerded deviation $\quad$ the measurement unit is $\mathrm{mg} / \mathrm{gm}$ tissue 
Table (8): Pearson chi-square statistical analysis of light microscopic findings in thyroid gland

\begin{tabular}{|l|c|c|c|c|c|c|}
\hline \multicolumn{1}{|c|}{ Group } & GroupI & GroupII & GroupIII & GroupIV & GroupV & Chi-Square \\
\hline $\begin{array}{l}\text { numanges } \\
\text { sized follicles }\end{array}$ & $0 \%$ & $20 \%$ & $20 \%$ & $66.7 \%$ & $22.2 \%$ & $\begin{array}{c}\mathrm{X}^{2}=8.59 \\
\mathrm{P}=0.72\end{array}$ \\
\hline reduction of colloid & $0 \%$ & $0 \%$ & $40 \%$ & $88.9 \%$ & $55.6 \%$ & $\begin{array}{c}\mathrm{X}^{2}=15.61 \\
\mathrm{P}=0.004^{*}\end{array}$ \\
\hline $\begin{array}{l}\text { flattened epithelial } \\
\text { lining }\end{array}$ & $20 \%$ & $20 \%$ & $20 \%$ & $88.9 \%$ & $44.4 \%$ & $\begin{array}{c}\mathrm{X}^{2}=10.77 \\
\mathrm{P}=0.03^{*}\end{array}$ \\
\hline $\begin{array}{l}\text { membrane } \\
\text { disruption }\end{array}$ & $0 \%$ & $\mathbf{0} \%$ & $0 \%$ & $55.6 \%$ & $0 \%$ & $\begin{array}{c}\mathrm{X}^{2}=15.71 \\
\mathrm{P}=0.003^{*}\end{array}$ \\
\hline $\begin{array}{l}\text { vascular congestion } \\
\text { Wide inter-follicular } \\
\text { area }\end{array}$ & $0 \%$ & $40 \%$ & $0 \%$ & $100 \%$ & $0 \%$ & $\begin{array}{c}\mathrm{X}^{2}=24.35 \\
\mathrm{P}=0.000^{*}\end{array}$ \\
\hline
\end{tabular}
${ }^{*} p<0.05$ is significant

Table (9): Pearson chi-square statistical analysis of light microscopic findings in pancreas

\begin{tabular}{|l|c|c|c|c|c|c|}
\hline \multicolumn{1}{|c|}{ Group } & GroupI & GroupII & GroupIII & GroupIV & GroupV & $\begin{array}{c}\text { Chi- } \\
\text { Square }\end{array}$ \\
\hline Widening of the inter-lobular spaces & $0 \%$ & $20 \%$ & $20 \%$ & $44.4 \%$ & $22.2 \%$ & $\begin{array}{c}\mathrm{X}^{2}=3.72 \\
\mathrm{P}=0.45\end{array}$ \\
\hline Vacuolar degeneration & $0 \%$ & $0 \%$ & $0 \%$ & $22.2 \%$ & $0 \%$ & 5.68 \\
\hline Congestion \& inflammation & $0 \%$ & $20 \%$ & $0 \%$ & $44.4 \%$ & $0 \%$ & 9.49 \\
\hline $\begin{array}{l}\text { Cells with deeply acidophilic cytoplasm and } \\
\text { dense small nuclei }\end{array}$ & $0 \%$ & $0 \%$ & $0 \%$ & $33.3 \%$ & $0 \%$ & $8.05^{*}$ \\
\hline
\end{tabular}
${ }^{*} p<0.05$ is significant

Table (10): One way ANOVA statistical analysis of thyroid IRS in different experimental groups

\begin{tabular}{|l|c|l|l|l|c|}
\hline \multirow{2}{*}{ Mean \pm SD } & \multicolumn{4}{|c|}{$\mathbf{P}<\mathbf{0 . 0 5}^{*}$} \\
\cline { 3 - 6 } & & vs II & vs III & vs IV & vs V \\
\hline Group I & $3.4 \pm 0.89$ & 0.9 & 0.91 & $0.01^{*}$ & $0.005^{*}$ \\
\hline Group II & $3.2 \pm 0.84$ & & 0.89 & $0.03^{*}$ & $0.002^{*}$ \\
\hline Group III & $3.0 \pm 1.0$ & & & $0.05^{*}$ & $0.001^{*}$ \\
\hline Group IV & $0.78 \pm 0.67$ & & & & $0.001^{*}$ \\
\hline Group V & $6.33 \pm 2.18$ & & & & \\
\hline
\end{tabular}

${ }^{*} p<0.05$ is significant

SD: standerded deviation

Table (11): One way ANOVA statistical analysis of pancreatic IRS in different experimental groups

\begin{tabular}{|l|c|l|l|l|l|}
\hline \multirow{2}{*}{ Mean \pm SD } & \multicolumn{5}{c|}{ P> 0.05 } \\
\cline { 4 - 6 } & vs II & vs III & vs IV & vs V \\
\hline Group I & $1.6 \pm 0.54$ & 0.89 & 0.9 & 0.71 & \\
\hline Group II & $1.4 \pm 0.55$ & & 0.91 & 0.88 & 0.86 \\
\hline Group II & $1.41 \pm 0.5$ & & & 0.89 & 0.87 \\
\hline Group V & $1.11 \pm 0.78$ & & & & 0.29 \\
\hline
\end{tabular}

${ }^{*} p<0.05$ is significant

SD: standerded deviation 

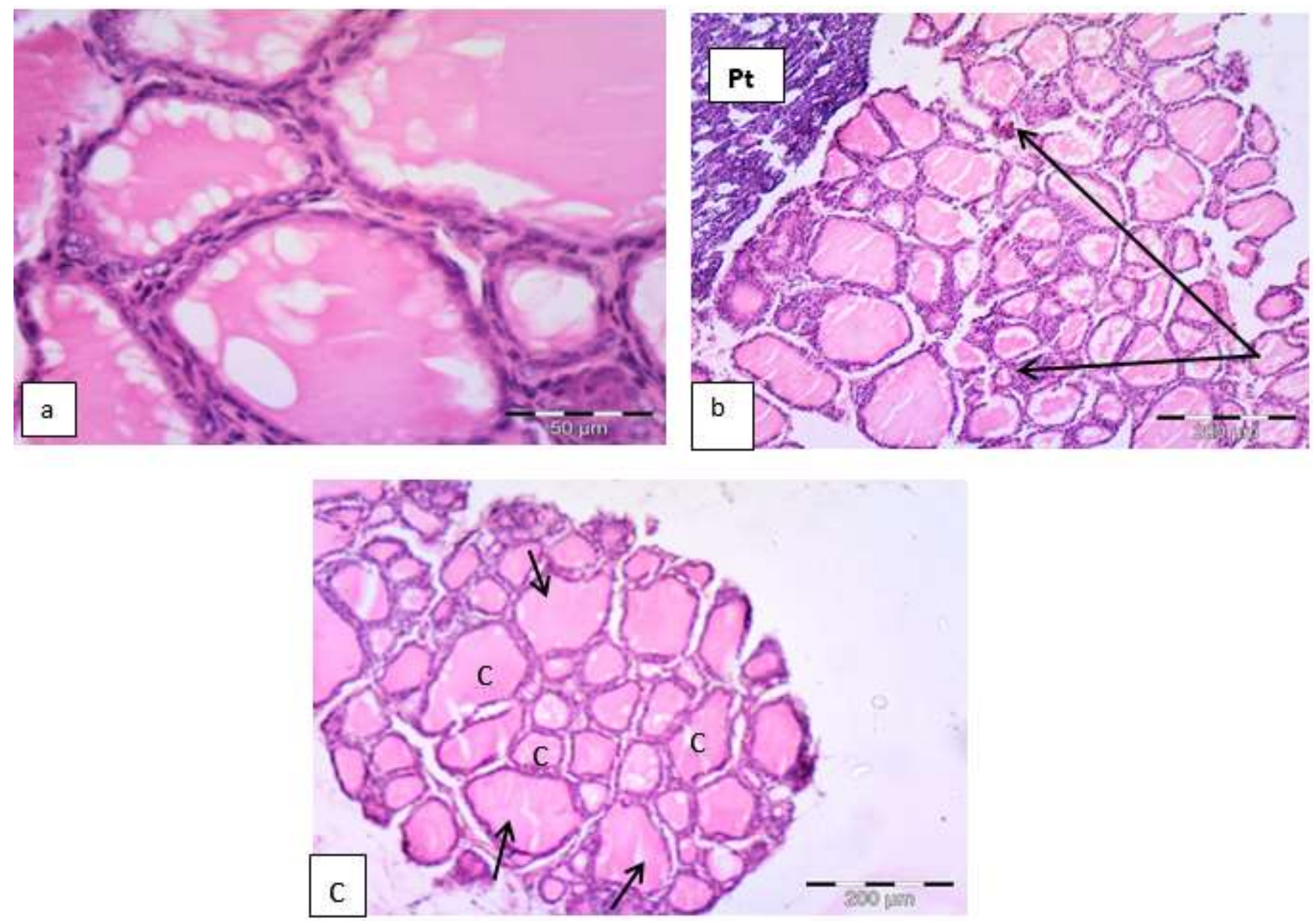

Fig.1: photomicrograph of rat thyroid tissue showing: a) Group I: different-sized follicles separated by inter follicular cells. The lumina filled with colloid. follicles lined by a single layer of cuboidal epithelium or flat cells (H\&Ex400). b) Group II: normal lobular (arrows) architecture with variable-sized follicles, Pt; parathyroid gland (H\&Ex100). C) Group III: normal lobular architecture; variable-sized follicles filled with colloid (c), the large follicles at periphery of lobules (black arrows) (H\&Ex100).
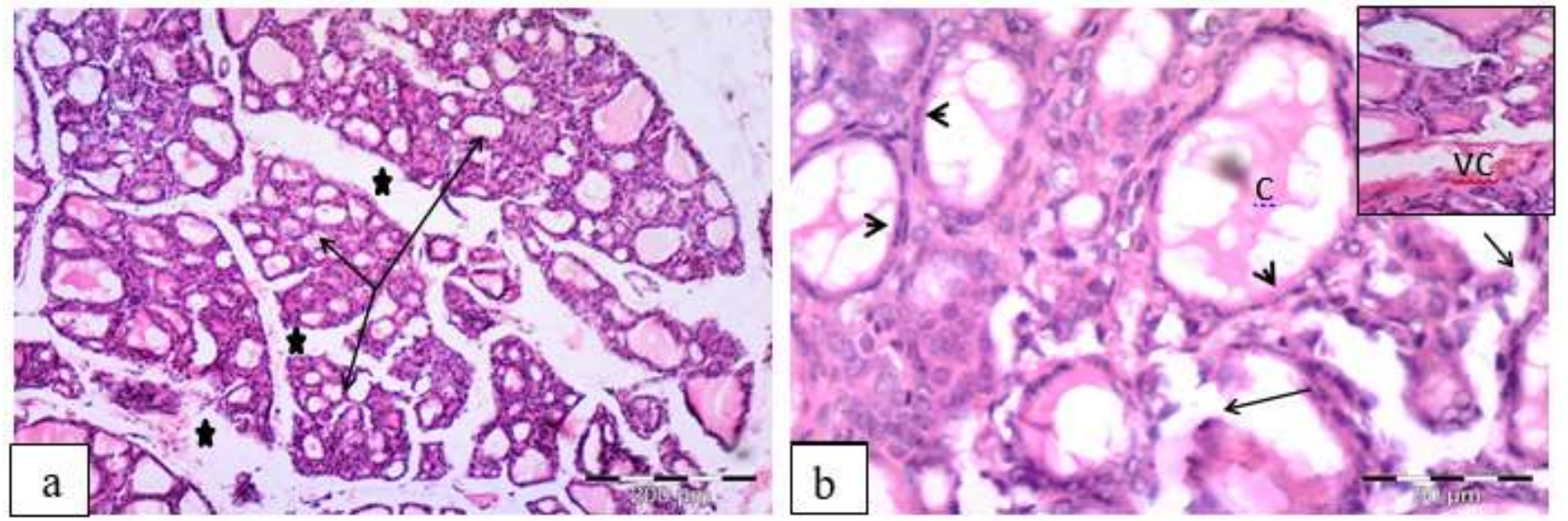

Fig.2: photomicrograph of rat thyroid gland of group IV showing: a) widening of interlobular areas (stars), numerous small sized follicles (arrows) with decreased colloid, and increased interfollicular tissue (H\&Ex100). b) Flattening of most cells lining the follicles (arrowheads), disrupted basement membrane (arrow), and decreased colloid (c). Inset showing vascular congestion (vc) and some desquamated cells in the lumen (circle) (H\&E x400). 


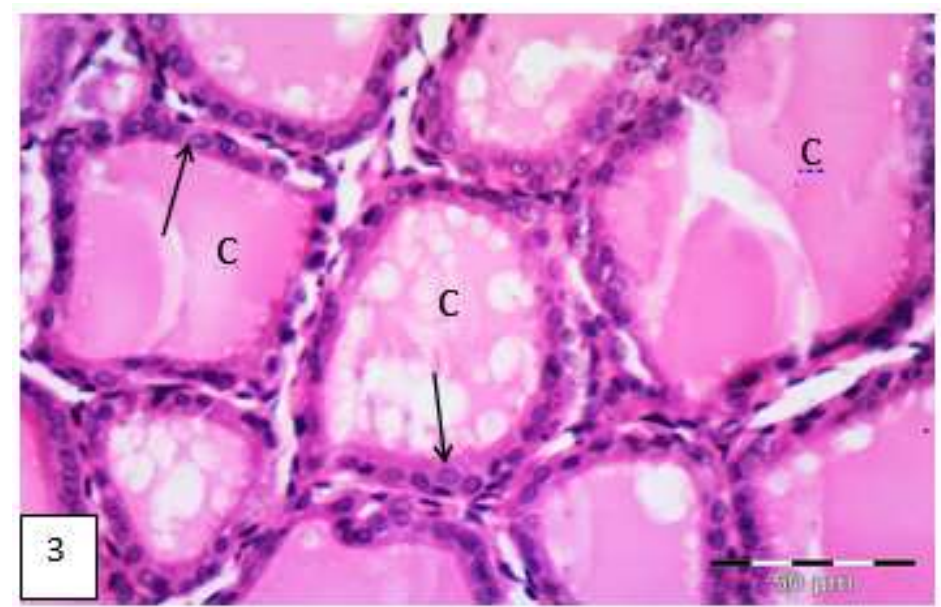

Fig.3: photomicrograph of rat thyroid gland of group $\mathrm{V}$ showing: Thyroid follicles lined mostly by a single layer of cubical cells (arrows).Notice colloid (C) and intact follicular wall.P; interfollicular cells (H\&Ex400).
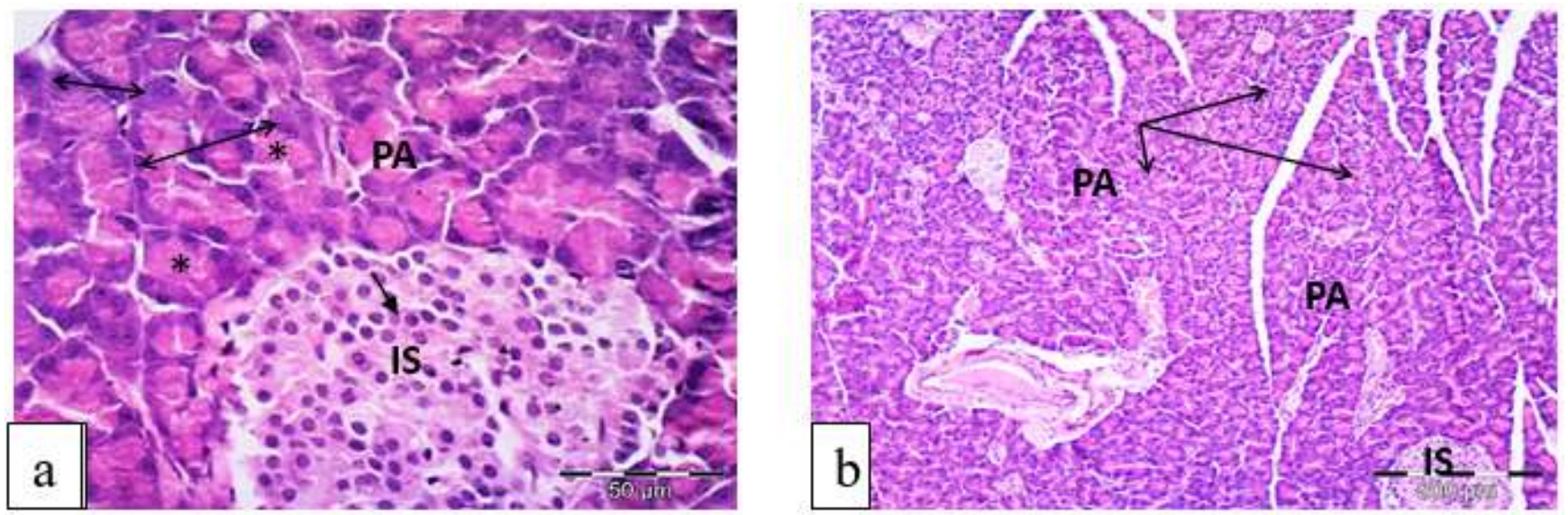

Fig. 4: photomicrograph of rat pancreatic tissue showing: a) Group I: Islet (IS) surrounded by numerous acini (PA). Islet's cells arranged in cords (arrow) and the acinar cells shows basal basophilic (double head arrows) and apical acidophilic cytoplasm (*) (H\&Ex400). b) Group II \& III: normal lobular (arrows) architecture; islets of Langerhans (IS) and the pancreatic acini (PA) (H\&Ex100).
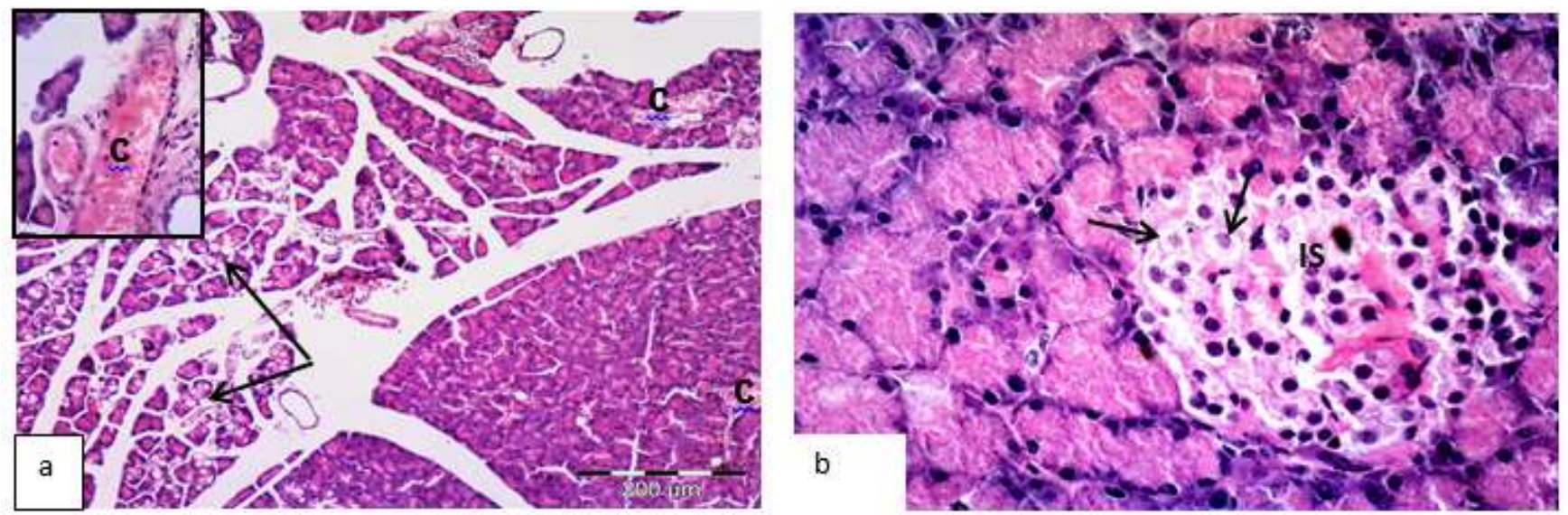

Fig. 5: photomicrograph of rat pancreatic tissue of the group IV showing: a) widening of interlobular spaces, lobular vacuolization (arrows), and vascular congestion (C\& inset) (H\&Ex400). b) Degenerated islet (IS) shows cells with vacuolated cytoplasm and degenerated nuclei (arrows) and some cells with deeply acidophilic cytoplasm and dense small nuclei (arrows) (H\&Ex400). 


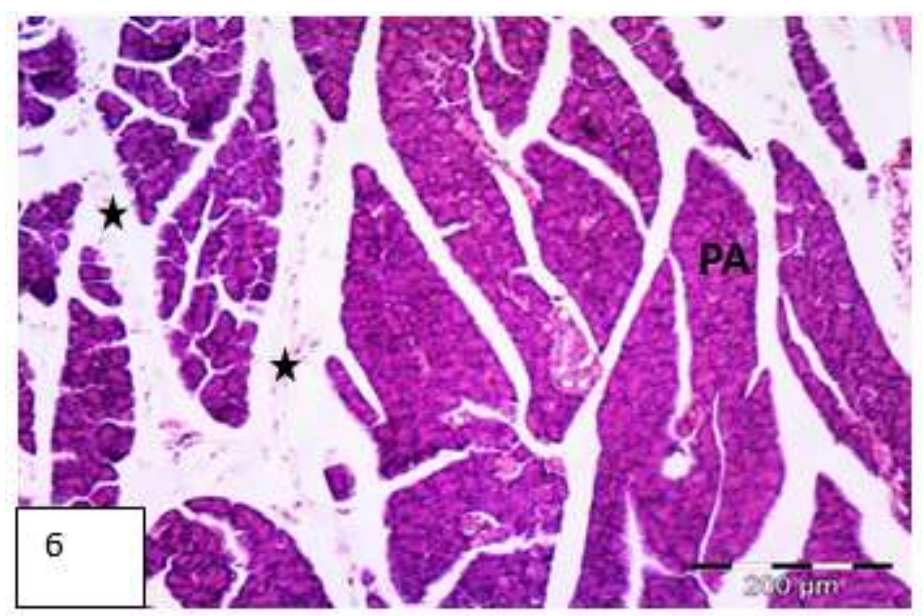

Fig. 6: A photomicrograph of rat pancreatic tissue of the group $\mathrm{V}$ showing: normal lobular (arrows) architecture; islets of Langerhans (IS) and the pancreatic acini (PA). Notice widinning of the interlobular tissue (stars) (H\&Ex100).
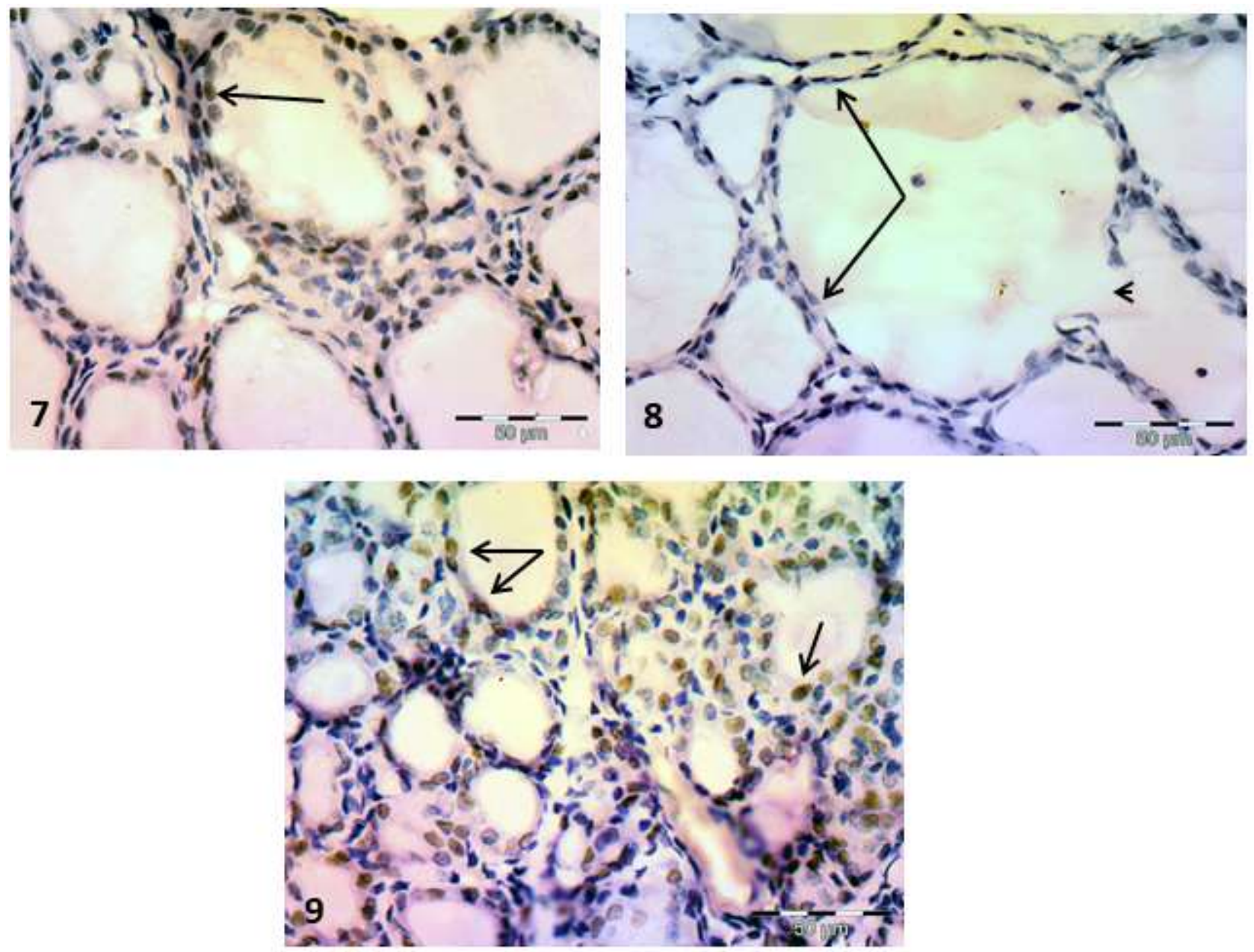

Photomicrographs of rat thyroid tissue immunostained for PCNA, showing: Fig.7) Group I, II, III with some immunolabeled cells (arrows). Fig.8) Group IV: no immunolabeling of cells, flattening of most cells (arrow) and disruption of epithelial lining (arrowhead). Fig.9) Group V: increased immunolabeling of cells (arrows). (Immunohistochemistry $X$ 400) 

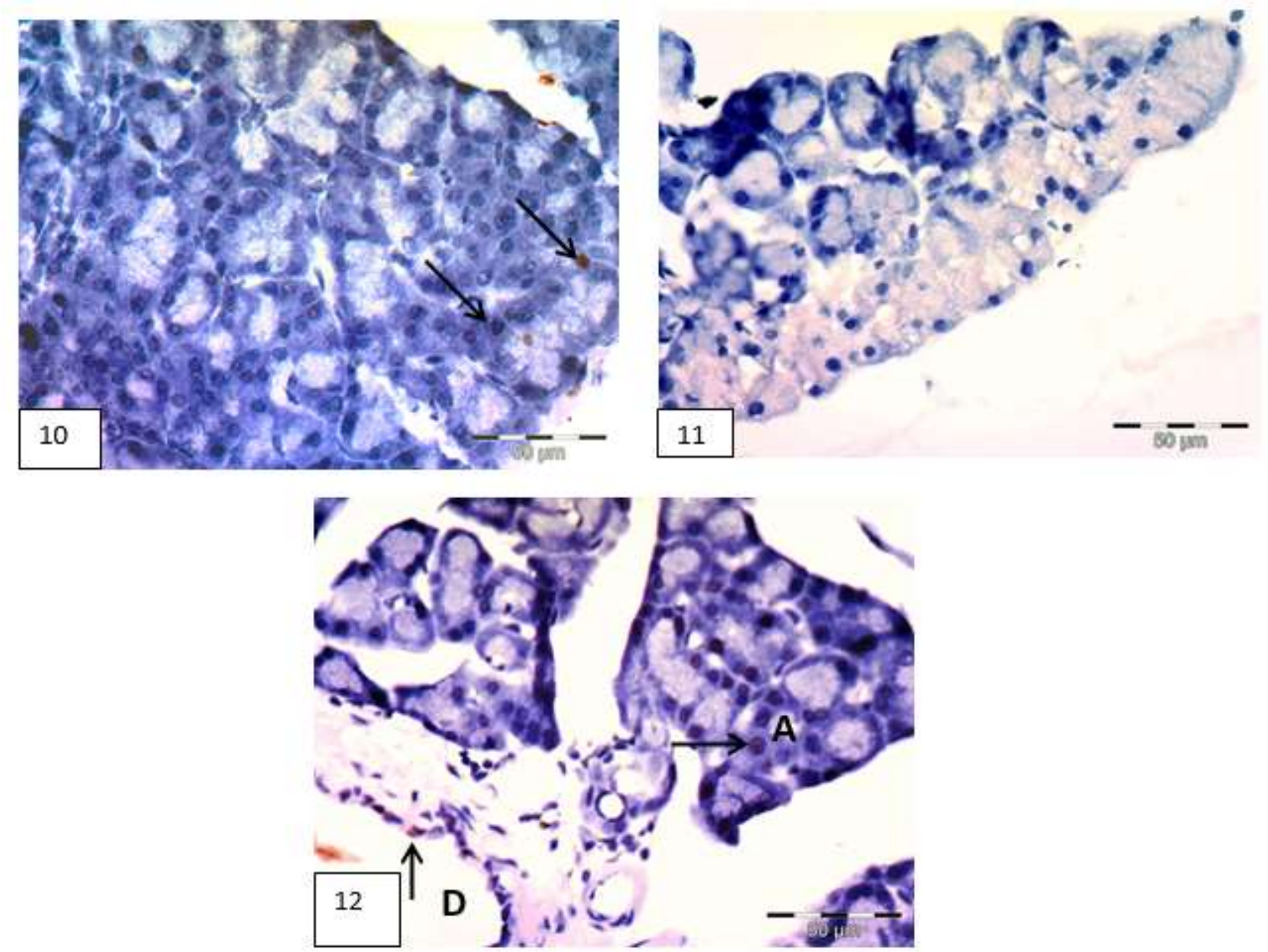

Photomicrographs of rat pancreatic tissues immunostained for PCNA showing: Fig.10) Group I, II \&III with few immunolabeled cells (arrows). Fig.11) Group IV: no immunolabeling of cells. Fig.12) Group V: showing some immunolabeled cells (arrows) of the acini (A) and duct (D). (Immunohistochemistry X 400).

\section{Discussion}

Carrageenan is a high molecular weight sulfated polysaccharide that is derived from seaweeds. It is important to realize that it is widely used for two main purposes; in conventional medicine as it used to decrease pain and swelling. It can also be used in its acidic form as a bulk laxative and to treat peptic ulcers. It is used as a food additive and a thickening and firming agent as in healthcare products like toothpaste, industrial vinegar production and fermented milk products (Tobacman, 2001).

There are many dangers and side effects of seaweed food additive as carageenan e.g. ulcerative colitis, large bowel ulceration, fetal toxicity and birth defects, liver cancer and immune suppression when administered intravenously and not when consumed as a food additive (Bhatlacharyya et al., 2012). Carageenan rarly causes acute toxicity due to its molecular weight. It is not significantly absorbed or metabolized by human bodies, which basically means that it flows through the GIT like most other fibers and it is excreted in the feaces (Blakemore and Harpell, 2010).
Diacerein (diacetylrhein) is a slow acting drug of the class anthraquinone that is used to treat joint diseases such as osteoarthritis. It has antioxidant and anti-inflammatory effects. It acts by blocking the action of interleukin-1beta which is a protein involved in the inflammatory process. It doesn't inhibit prostaglandins, so it doesn't have a deleterious effect on the upper GIT (Panova et al., 2015). The objective of this study was to assess the effects of chronic carrageenan exposure on thyroid gland and pancreas, and evaluate the influence of diacerein administration on these effects.

The results of the present study clearly demonstrated that carrageenan administration causes hypothyroidism which is suspected biochemically and ensured from the histopathological and immunohistochemistry findings. However, diacerein administration reversed such thyroid changes produced by carrageenan.

In this study, T4 was decreased significantly due to oral intake of carrageenan and that results are in accordance with Jatwa \& Kar, (2009), who observed 
significant decrease in the serum concentrations of $\mathrm{T} 4$ following carrageenan administration. Carrageenan is known to induce inflammation, which resulted in depressed activity of thyroid gland (Borthakur et al., 2007). Carrageenan-induced hypothyroidism appears to be an outcome of increased IL-1 level, which in turn decreases serum concentration of T4 and T3 (Singh et al., 2014). The level of serum $\mathrm{T} 4$ level was significantly increased by administration of diacerein in group V. Jatwa \& Kar, (2009) found that the levels of both thyroid hormones were regulated after diacerein administration. Their study concluded that administration of diacerein with Carageenan regulates thyroid functions both at the glandular level (the only source of T4 generation) and at the level of peripheral conversion of T4 to T3 (the major process of $\mathrm{T} 3$ formation).

Chronic carrageenan toxicity did not affect serum T3 in this study, in which there was insignificant decrease in serum T3 level in carrageenan treated group and in diacerein + carrageenan treated group. This finding is not agree with results of Jatwa \& Kar, (2009), whose study revealed that carrageenan caused significant decrease in serum T3 and T4 levels. An assessment of serum free $\mathrm{T} 4$ is the primary test for detecting hypothyroidism. However, serum T3 measurement, whether total or free, has limited utility in hypothyroidism because levels are often normal due to hyperstimulation of the remaining functioning thyroid tissue by elevated TSH and to up-regulation of type 2 iodothyronine deiodinase and so it is preferred to assess serum T4 (Garber et al., 2012).

Regarding, serum amylase level evaluation, insignificant decrease in serum amylase level was observed in carrageenan treated group and this decrease did not changed by administration of diacerein. These results are in agreement with Weiner et al. (2007), who reported that carrageenan did not affect the pancreatic tissue and the serum amylase level.

As regards MDA and GSH levels, there was significant increase in MDA level and significant decrease in GSH level in thyroid gland in carrageenan group, and MDA level was significantly decreased by administration of diacerein before carageenan in group $\mathrm{V}$ compared to diacerein treated group and the level of GSH increased in diacerein + carrageenan group but still not reached to control level. These findings are agreed with results of Jatwa \& Kar, (2009), who found an increase MDA level and decrease GSH level in hepatic, renal and cardiac tissues and diacerein in their sudy has a protective effect. The results of this present study revealed that there was insignificant increase in MDA and insignificant decrease in GSH levels in pancreatic tissues in all groups compared to control group and these changes did not changed by administration of diacerein. Investigation of MDA and GSH levels in pancreas in this present study, revealed insignificant changes.

Carrageenan group had variable and patchy morphological changes in thyroid gland. Contrary to these current findings, Weiner, (2014), demonstrated that sub-chronic and chronic CGN did not result in thyroid toxicity or any microscopic abnormality in examined thyroid tissues. Subchronic and chronic administration of CGN in the diet to several species, in well-conducted studies, did not result in adverse effects other than soft stools or diarrhea. These effects are commonly seen when dietary fibers are fed at high doses (Tungland \& Meyer, 2002).

PCNA immunoreactivity was observed in low score in rats fed on carregeenan. An important explanation for these findings is what observed by Ariffin et al. (2014) who reported that $k$-carrageenan inhibited cell proliferation and the anti-proliferative effect was related to apoptosis together with inactivation of cell proliferating genes. PCNA has been found to be a useful marker in immunocytochemical studies of cell proliferation because its expression correlates with the proliferative state of the cell (Meresman et al., 2010).

Expression of the proliferative marker (PCNA) in thyroid significantly increased after diacerin administration in this present research, and these results are in contrary with Lohberger et al. (2015), who suggested that diacerein has anti-proliferative activities. Their research discussed the action of diacerein on tumor cells.

Amelioration of carrageenan induced thyroid histopathological changes following diacerin administration could be the resultant of diacerein-induced inhibition in IL-1b synthesis which was increased by carrageenan as suggested by Mahajan et al. (2006). Diacerein might be acting through activation in the synthesis and/or secretion of circulating thyroid hormones, which in turn stimulate the anti-peroxidative and anti-inflammatory responses (Braverman \& Burman 2017 ; Jatwa \&Kar, 2009).

Regarding pancreas, the present study revealed no significant statistical abnormality in serum amylase levels or microscopical and immunohistochemical examination of pancreatic tissues of carrageenan group, and these results are in agreement with Weiner et al., (2007), who reported that no carrageenan treatmentrelated microscopic abnormality was detected in examined pancreatic tissues.

\section{Conclusion \& Recommendation}

Finally, it is concluded that chronic toxicity of carrageenan can cause many hazardous effects. And, from this present study, it is approved that chronic administration of carrageenan caused hypothyroidism both histologically and biochemically. Diacerein had a protective role on carrageenan induced hypothyrodism through its antiperoxidative and anti inflammatory effects.

So, it is recommended to address public associations for raising awareness against hazards of carrageenan. Also, it is advised to use diacerein as a protective agent against carrageenan toxicity. Finally, the results of this study emphasize the need for future 
researches on other hazardous effects of carrageenan on other body organs and glands.

\section{References}

Ariffin SZ, Yeen WW, Abidin IZ et al. (2014): Cytotoxicity effect of degraded and undegraded kappa and iota carrageenan in human intestine and liver cell lines. BMC complement altern Med. 14: pp. 508.

Bancroft JD, Stevens A and Turner DR (2002): Theory and practice of histological techniques. $4^{\text {th }}$ ed., New York: Churchill Livingstone, Ch 3.pp. 564388.

Beutler E, Duron O, Kelly MB (1963):.J. Lab. Clin. Med . 61: pp. 882.

Bhatlacharyya S, O-Sullivan I, Katyal S et al., (2012): Exposure to the common food additive carrageenan leads to glucose intolerance, insulin resistance and inhibition of insulin signaling in $\mathrm{HepG}_{2}$ cells and C57BL/ 6J mice. Diabetologia. 55(1):pp. 194-203.

Biely P, Mislovicova D, Markovic O et al., (1988): A New Chromogenic Substrate for Assay and Detection of alpha-Amylase. Anal Biochem. 172 : pp.176.

Blakemore WR and Harpell AR (2010): Carrageenan. In: Imeson A, ed. Food Stabilisers, Thickeners and Gelling Agent, Chapter 5. WileyBlackwell, Blackwell Publishing Ltd. Published Online. pp. 73-94.

Borthakur A, Bhattacharyya S, Dudeja PK et al., (2007): Carrageenan induces interleukin-8 production through distinct Bcl10 pathway in normal human colonic epithelial cells. Am J Physiol Gastrointest Liver Physiol. 292(3): pp. 829-38.

Braverman LE, and Burman KD (2017): What is the clinical role of oral liquid preparations in the treatment of patients with hypothyroidism? Endocr Pract. 23 (2): pp. 243-244.

Chen, Yuan, Zha et al., (2017) : Developmental toxicity and thyroid hormone-disrupting effects of 2,4dichloro-6-nitrophenol in Chinese rare minnow (Gobiocypris rarus). in: Aquatic toxicology (Amsterdam, Netherlands). 185: pp. 40-47.

El-Tahawy NF, Rifaai RA, Saber EA et al., (2017): Effect of Platelet Rich Plasma (PRP) Injection on the Endocrine Pancreas of the Experimentally Induced Diabetes in Male Albino Rats: A Histological and Immunohistochemical Study. J Diabetes Metab. 8(3): pp.730-9.

Garber JR, Cobin RH, Gharib H, et al., (2012): Clinical practice guidelines for hypothyroidism in adults: cosponsored by the American Association of Clinical Endocrinologists and the American Thyroid Association. Thyroid. 22(12): pp. 1200-35.
Jatwa R and Kar A (2009): Anti-inflammatory and antiperoxidative roles of diacerein are possibly mediated through an alteration in thyroid functions in animal model of inflammation. Fundamental \& Clinical Pharmacology. 23: pp. 465-471.

Lai VMF, Wong PAL, Lii CY (2000): Effects of cation properties on 501 gel transition and gel properties of K- carrageenan. Journal of food science. 65: pp. 1332-1337.

Lohberger B, Leithner A, Stuendl N et al., (2015): Diacerein retards cell growth of chondrosarcoma cells at the G2/M cell cycle checkpoint via cyclin B1/CDK1 and CDK2 downregulation. BMC cancer. 15: pp. 891.

Mahajan A, Singh K, Tandon VR et al., (2006): Diacerein: a new symptomatic slow acting drug for osteoarthritis. J. K. Sci. 8: pp.173-175.

Marwa MM, Entesar F, Nashwa F, et al., (2016): Possible protective effect of Diacerein on doxorubicininduced nephrotoxicity in rats. Journal of toxicology. 2016: pp. 1-9.

Meresman GF, Olivares C, Vighi S et al., (2010): Apoptosis is increased and cell proliferation is decreased in out-of-phase endometria from infertile and recurrent abortion patients.Reprod Biol Endocrinol. 8: pp. 126.

Metindir J, Dilek GB, Pak I (2008): Staining characterization by immunohistochemistry of tumor cancer antigen in patients with endometrial cancer. Eur J Gyneacol Oncol. 29(5): pp. 489-92.

Necas J and Bartosikova L (2013): Carrageenan: a review. Veterinarni Medicina. 5 (4): pp. 187205.

Ohkawa H, Ohishi W ,Yagi K (1979): Biochem . 95: pp. 351.

Panova, Elena, Jones et al., (2015): Benefits- risk assessment of diacerein in the treatment of osteoarthritis. Drug Safety. 38 (3): pp. 245-252.

Pavelka K, Toma's T, Karpas K et al., (2007): The Efficacy and Safety of Diacerein in the Treatment of Painful Osteoarthritis of the Knee A Randomized, Multicenter, Double-Blind, Placebo-Controlled Study With Primary End Points at Two Months After the End of a ThreeMonth Treatment Period. Arthritis \& Rheumatism. 56 (12): pp. 4055-4064.

Singh A, Padder R, Jatwa R et al., (2014): Amelioration of carrageenan-induced inflammation and hypothyrodism by Etoricoxb, A COX-2 inhibitor in rat model. World journal of pharmacy and pharmaceutical sciences. 3 (7): pp. 1671-1684.

Strzalka W and Ziemienowicz A (2011): Proliferating cell nuclear antigen (PCNA): a key factor in DNA replication and cell cycle regulation. Ann Bot. 107(7): pp. 1127-1140. 
